\title{
Preliminary results on epidemiology of Coconut Lethal Yellowing in Ghana
}

\author{
François BONNOT ${ }^{1}$ \\ Gilbert DANYO ${ }^{2}$ \\ René PHILIPPE ${ }^{3}$ \\ Sylvester DERY ${ }^{2}$ \\ Arthur RANSFORD ${ }^{4}$ \\ ${ }^{1}$ CIRAD, UPR Etiologie Dépérissements, \\ Avenue Agropolis, 34398 Montpellier Cedex 5, \\ France \\ <francois.bonnot@cirad.fr> \\ 2 OPRI, P.O. Box 245, Sekondi, Ghana \\ ${ }^{3}$ CIRAD, UPR Etiologie Dépérissements, \\ P.O. Box 245, Sekondi, Ghana \\ ${ }^{4}$ CSDP, P.O. Box 245, Sekondi, Ghana
}

\begin{abstract}
Epidemiological studies are of major importance in understanding the determinants of plant diseases in order to control the risks of their spreading. A research programme on the epidemiology of coconut lethal yellowing, or Cape Saint Paul Wilt Disease (CSPWD), in Ghana was launched in March 2007. The objective was to characterize the distribution and spread of the disease in space and time at various scales, and their relation with the environment. This article presents the general strategy used to evaluate the incidence of CSPWD along with the environmental, ecological and agronomical variables at regional level. A survey was undertaken on 1,166 plots of Coconut Sector Development Project (CSDP) planted with Malayan Yellow Dwarf (MYD) $\times$ Vanuatu Tall (VTT) hybrids in Western Region and Central Region. Preliminary results on the distribution of CSPWD and outside variables at regional scale, along with their relations, are given.
\end{abstract}

Key words: coconut, Lethal Yellowing, Cape Saint Paul Wilt Disease, epidemiological survey
Epidemiological studies are of major importance in understanding the determinants of plant diseases in order to control the risks of their spreading. Over the last 10 years, the Oil Palm Research Institute (OPRI) and the Centre de Coopération Internationale en Recherche Agronomique pour le Développement (CIRAD) made few observations on the distribution and spread in space and time of coconut lethal yellowing, or Cape Saint Paul Wilt Disease (CSPWD), and on the relations of the disease with the environment. However, worth mentioning is the work undertaken to monitor the phytosanitary condition of several hundred coconut palms at Ayensudu (Central Region) for several months between 1992 and 1994, and the annual plot records kept between 1993 and 2000 on around a thousand plots [5]. But those observations, however interesting they might be, were not very precise, and provided mainly qualitative knowledge about the epidemiology of CSPWD: they showed that the disease can start from a few infested coconut palms and that it spreads by leaps over variable distances, in any direction and also that foci occur in patches that can sometimes merge. Few quantitative data about the disease are available. For example, the incidence of the disease or the speed with which it spreads at a given site or for a given variety of coconut palm are rarely known, yet those parameters are necessary for estimating the risk of the disease spreading to a neighbouring site. In addition, the appearance and development of the disease result from changes in a complex system, which probably brings into play a multitude of outside factors that may be biotic (wild flora, intercrops, fauna) or abiotic (climate, hydrography, topography, soil and so forth), in addition to the three components, coconutvector-phytoplasma. The observations carried out in these plots cannot therefore be used to relate the disease to outside variables or steer research towards one avenue rather than another. Consequently, in order to provide a scientific conclusion backed up by a statistical analysis, it is necessary to carry out more numerous and more structured observations. A research programme on the epidemiology of coconut lethal yellowing or CSPWD in Ghana was launched in March 2007 [2]. The objective was to characterize the distribution and spread of the disease in space and time at various scales, and their relation with the environment. This article gives preliminary results on the distribution of CSPWD and outside variables at regional scale, along with their relations.

\section{Material and methods}

\section{Plots}

Between April 1999 and the end of 2004, 1,300 hectares of MYD $\times$ VTT hybrids divided between 1,166 one- to two-hectare plots on 1,012 farms were planted in the Central and Western regions as part of a project assigned to the Coconut Sector Development Project (CSDP) with funding from Agence Française pour le Développement (AFD). The MYD $\times$ VTT hybrid had been recommended for its good agronomic performance and assumed resistance to CSPWD. It subsequently proved to be quite susceptible to the disease.

\section{Data collection}

A questionnaire was established in order to obtain information from every plot of the CSDP project. Categories of data were plot identity, hydrography, topography, soil, agronomical and ecological data, agronomical and diseased situation around the plot. Each category contained a set of questions simple enough to be answered by discussion with the farmer and observation of the plot. The survey based on the questionnaire was launched in April 2007, involving six technical officers (TO). Each TO was in charge of, approximately, one district. Each farmer was visited by a TO. During the visit, the precise geographical location was spotted with a Global Positioning System (GPS receiver). Phytosanitary data, including the numbers of planted and diseased trees, were collected apart from the questionnaire. Data of the questionnaire (outside variables), GPS coordinates and phytosanitary data were merged into a unique file in order to be analysed. Because of correspondence problems not yet solved between the three original data 
sets, not all the data could be used for this preliminary study. Data available concern 881 questionnaires with identified GPS coordinates, 597 questionnaires with identified phytosanitary data, 590 questionnaires with both GPS coordinates and phytosanitary data, 36 plots with lethal yellowing, 30 plots with lethal yellowing and GPS coordinates.

\section{Data analysis}

Only preliminary descriptive analyses of outside variables were performed. Outside variables were tabulated and crossed with districts.
Independence of district and outside variables was tested using the Fisher's exact test [1]. Two definitions of incidence of the disease were used [3]. Within a group of plots, "Tree incidence" was defined as the ratio of the number of trees infected or dead divided by the number of planted trees. "Plot incidence" was defined as the number of attacked plots divided by the total number of plots within the group. In the latter case, a plot is considered as attacked if at least one palm is attacked by the disease. GPS coordinates of the plots were used to map the healthy and diseased plots along with incidence. Independence between out- side variables and Plot incidence was tested using Fisher's exact test. Effect of outside variables on Tree incidence was tested using a logistic regression with estimation of overdispersion parameter [4].

\section{Results}

\section{Outside variables}

The distribution of plots according to outside variables and districts is presented in tables 1 to 6. Fisher's exact test rejected independence between district and every outside variable at

Table 1. Distribution of plots according to planting year and district.

\begin{tabular}{|c|c|c|c|c|c|c|c|c|c|c|c|c|}
\hline \multirow{2}{*}{$\begin{array}{l}\text { Year } \\
1999\end{array}$} & \multicolumn{2}{|c|}{ Nzema East } & \multicolumn{2}{|c|}{ Wassa West } & \multicolumn{2}{|c|}{ Ahanta West } & \multicolumn{2}{|c|}{ SAEMA } & \multicolumn{2}{|c|}{ KEEA } & \multicolumn{2}{|c|}{ AAK } \\
\hline & 0 & 0.000 & 0 & 0.000 & 11 & 0.125 & 1 & 0.007 & 11 & 0.046 & 0 & 0.000 \\
\hline 2000 & 109 & 0.399 & 7 & 0.103 & 41 & 0.466 & 16 & 0.117 & 39 & 0.165 & 10 & 0.109 \\
\hline 2001 & 6 & 0.022 & 3 & 0.044 & 27 & 0.307 & 32 & 0.234 & 28 & 0.118 & 21 & 0.228 \\
\hline 2002 & 58 & 0.212 & 31 & 0.456 & 3 & 0.034 & 12 & 0.088 & 68 & 0.287 & 19 & 0.207 \\
\hline 2003 & 10 & 0.037 & 6 & 0.088 & 4 & 0.045 & 70 & 0.511 & 80 & 0.338 & 31 & 0.337 \\
\hline 2004 & 90 & 0.330 & 21 & 0.309 & 2 & 0.023 & 6 & 0.044 & 11 & 0.046 & 11 & 0.120 \\
\hline
\end{tabular}

In each district, left column refers to number of plots and right column to proportion of plots in the district.

Table 2. Distribution of plots according to hydrography variables and district.

\begin{tabular}{|c|c|c|c|c|c|c|c|c|c|c|c|c|}
\hline \multirow{2}{*}{$\begin{array}{l}\text { Hydrography variables } \\
\text { Presence of water }\end{array}$} & \multicolumn{2}{|c|}{ Nzema East } & \multicolumn{2}{|c|}{ Wassa West } & \multicolumn{2}{|c|}{ Ahanta West } & \multicolumn{2}{|c|}{ SAEMA } & \multicolumn{2}{|c|}{ KEEA } & \multicolumn{2}{|c|}{ AAK } \\
\hline & & & & & & & & & & & & \\
\hline No water & 141 & 0.516 & 62 & 0.912 & 53 & 0.602 & 55 & 0.401 & 35 & 0.148 & 27 & 0.293 \\
\hline River & 82 & 0.300 & 5 & 0.074 & 14 & 0.159 & 46 & 0.336 & 38 & 0.160 & 42 & 0.457 \\
\hline Swampy area & 50 & 0.183 & 1 & 0.015 & 21 & 0.239 & 36 & 0.263 & 164 & 0.692 & 23 & 0.250 \\
\hline \multicolumn{13}{|l|}{ Distance of water from the plot } \\
\hline Less than $10 \mathrm{~m}$ & 65 & 0.500 & 1 & 0.167 & 6 & 0.171 & 44 & 0.537 & 15 & 0.074 & 54 & 0.818 \\
\hline From 10 to $50 \mathrm{~m}$ & 35 & 0.269 & 3 & 0.500 & 11 & 0.314 & 30 & 0.366 & 54 & 0.267 & 7 & 0.106 \\
\hline More than $50 \mathrm{~m}$ & 30 & 0.231 & 2 & 0.333 & 18 & 0.514 & 8 & 0.098 & 133 & 0.658 & 5 & 0.076 \\
\hline \multicolumn{13}{|l|}{ Is the plot floodable? } \\
\hline Never & 209 & 0.913 & 64 & 0.941 & 46 & 0.730 & 117 & 0.907 & 214 & 0.907 & 50 & 0.549 \\
\hline Less than 1 week a year & 12 & 0.052 & 1 & 0.015 & 5 & 0.079 & 0 & 0.000 & 9 & 0.038 & 15 & 0.165 \\
\hline Between 1 week and 1 month a year & 3 & 0.013 & 3 & 0.044 & 9 & 0.143 & 12 & 0.093 & 13 & 0.055 & 25 & 0.275 \\
\hline More than 1 month a year & 5 & 0.022 & 0 & 0.000 & 3 & 0.048 & 0 & 0.000 & 0 & 0.000 & 1 & 0.011 \\
\hline
\end{tabular}

In each district, left column refers to number of plots and right column to proportion of plots in the district.

Table 3. Distribution of plots according to topography variables and district.

\begin{tabular}{|c|c|c|c|c|c|c|c|c|c|c|c|c|}
\hline \multirow{2}{*}{$\begin{array}{l}\text { Topography variables } \\
\text { Location of the plot }\end{array}$} & \multicolumn{2}{|c|}{ Nzema East } & \multicolumn{2}{|c|}{ Wassa West } & \multicolumn{2}{|c|}{ Ahanta West } & \multicolumn{2}{|c|}{ SAEMA } & \multicolumn{2}{|c|}{ KEEA } & \multicolumn{2}{|c|}{ AAK } \\
\hline & & & & & & & & & & & & \\
\hline In the bottom of a valley & 5 & 0.027 & 0 & 0.000 & 1 & 0.018 & 44 & 0.333 & 0 & 0.000 & 36 & 0.396 \\
\hline At the bottom of a slope & 2 & 0.011 & 2 & 0.053 & 9 & 0.158 & 43 & 0.326 & 40 & 0.199 & 11 & 0.121 \\
\hline Along a slope & 167 & 0.893 & 36 & 0.947 & 38 & 0.667 & 45 & 0.341 & 148 & 0.736 & 37 & 0.407 \\
\hline On top of a hill & 13 & 0.070 & 0 & 0.000 & 9 & 0.158 & 0 & 0.000 & 13 & 0.065 & 7 & 0.077 \\
\hline \multicolumn{13}{|l|}{ Slope } \\
\hline Flat & 102 & 0.382 & 39 & 0.574 & 33 & 0.379 & 78 & 0.569 & 190 & 0.819 & 16 & 0.302 \\
\hline Low & 80 & 0.300 & 19 & 0.279 & 21 & 0.241 & 50 & 0.365 & 14 & 0.060 & 13 & 0.245 \\
\hline Medium & 59 & 0.221 & 10 & 0.147 & 28 & 0.322 & 9 & 0.066 & 27 & 0.116 & 24 & 0.453 \\
\hline Steep & 26 & 0.097 & 0 & 0.000 & 5 & 0.057 & 0 & 0.000 & 1 & 0.004 & 0 & 0.000 \\
\hline
\end{tabular}

In each district, left column refers to number of plots and right column to proportion of plots in the district. 
level lower than 0.0001 , leading to the conclusion that districts are strongly characterized by the outside variables.

\section{Planting year}

In Ahanta West, most plots were planted between 1999 and 2001. In districts SAEMA, KEEA and AAK, planting occurred principally between 2000 and 2003, with a maximum in 2003. In Nzema East and Wassa West, most plots were planted in 2000, 2002 and 2004.

\section{Hydrography}

Western districts (Nzema East, Wassa West, Ahanta West) have more than $50 \%$ of the plots without presence of water $(91 \%$ of plots in Wassa West), whereas eastern districts (SAEMA, KEEA, AAK) have more than $50 \%$ of the plots with presence of water (only $14.8 \%$ of plots without water in KEEA). In AAK, $27.5 \%$ of the plots are floodable between 1 week and 1 month a year.

\section{Topography}

In districts Nzema East, Wassa West, Ahanta West and KEEA, more than $80 \%$ of the plots are located along a slope or on the top of a hill, with sometimes more than $30 \%$ of medium or steep slopes (Nzema East and Ahanta West). In SAEMA and AAK, more than $50 \%$ of the plots are located in the bottom of a valley or at the bottom of a slope.

\section{Soil}

In districts Nzema East, Wassa West and SAEMA, more than $80 \%$ of the plots have light-coloured soil and more than $80 \%$ have a soil with light texture. In KEEA and AAK, more than $40 \%$ of the plots have dark-coloured soil. In KEEA, $39 \%$ of the plots have a heavy texture and only $3 \%$ have no coarse elements, against more than $60 \%$ for the other districts. Ahanta West has intermediate characteristics, with $16 \%$ of plots with dark brown soil and $26 \%$ with heavy texture.

\section{Agronomical and ecological data}

Previous land occupation was principally forest in Nzema East, Wassa West and AAK, coconut in SAEMA and KEEA, oil palm and coconut in Ahanta West. Herbicide is used principally in Nzema East, Wassa West and AAK (around $20 \%$ of the plots). The best maintenance is observed in Nzema East, Wassa West and SAEMA,

Table 4. Distribution of plots according to soil variables and district.

\begin{tabular}{|c|c|c|c|c|c|c|c|c|c|c|c|c|}
\hline \multirow{2}{*}{$\begin{array}{l}\text { Soil variables } \\
\text { Soil colour }\end{array}$} & \multicolumn{2}{|c|}{ Nzema East } & \multicolumn{2}{|c|}{ Wassa West } & \multicolumn{2}{|c|}{ Ahanta West } & \multicolumn{2}{|c|}{ SAEMA } & \multicolumn{2}{|l|}{ KEEA } & \multicolumn{2}{|c|}{ AAK } \\
\hline & & & & & & & & & & & & \\
\hline Black & 1 & 0.004 & 2 & 0.029 & 6 & 0.068 & 1 & 0.007 & 0 & 0.000 & 37 & 0.402 \\
\hline Dark brown & 3 & 0.011 & 0 & 0.000 & 14 & 0.159 & 2 & 0.015 & 104 & 0.439 & 0 & 0.000 \\
\hline Dark grey & 28 & 0.103 & 0 & 0.000 & 0 & 0.000 & 11 & 0.080 & 19 & 0.080 & 3 & 0.033 \\
\hline Dark red & 2 & 0.007 & 0 & 0.000 & 7 & 0.080 & 0 & 0.000 & 25 & 0.105 & 0 & 0.000 \\
\hline Light brown & 52 & 0.190 & 16 & 0.235 & 36 & 0.409 & 17 & 0.124 & 60 & 0.253 & 28 & 0.304 \\
\hline Light grey & 151 & 0.553 & 41 & 0.603 & 15 & 0.170 & 106 & 0.774 & 1 & 0.004 & 20 & 0.217 \\
\hline light red & 36 & 0.132 & 9 & 0.132 & 10 & 0.114 & 0 & 0.000 & 28 & 0.118 & 4 & 0.043 \\
\hline \multicolumn{13}{|l|}{ Soil texture } \\
\hline Heavy & 54 & 0.199 & 6 & 0.088 & 23 & 0.261 & 3 & 0.022 & 93 & 0.392 & 20 & 0.217 \\
\hline Light & 218 & 0.801 & 62 & 0.912 & 65 & 0.739 & 134 & 0.978 & 144 & 0.608 & 72 & 0.783 \\
\hline \multicolumn{13}{|l|}{ Coarse elements } \\
\hline Absence & 139 & 0.509 & 40 & 0.588 & 57 & 0.648 & 132 & 0.964 & 8 & 0.034 & 58 & 0.630 \\
\hline Few & 100 & 0.366 & 28 & 0.412 & 24 & 0.273 & 3 & 0.022 & 228 & 0.962 & 34 & 0.370 \\
\hline Many & 34 & 0.125 & 0 & 0.000 & 7 & 0.080 & 2 & 0.015 & 1 & 0.004 & 0 & 0.000 \\
\hline
\end{tabular}

In each district, left column refers to number of plots and right column to proportion of plots in the district.

Table 5. Distribution of plots according to agronomical/ecological variables and district.

\begin{tabular}{|c|c|c|c|c|c|c|c|c|c|c|c|c|}
\hline \multirow{2}{*}{$\begin{array}{l}\text { Agronomical/ecological variables } \\
\text { Previous land occupation }\end{array}$} & \multicolumn{2}{|c|}{ Nzema East } & \multicolumn{2}{|c|}{ Wassa West } & \multicolumn{2}{|c|}{ Ahanta West } & \multicolumn{2}{|c|}{ SAEMA } & \multicolumn{2}{|c|}{ KEEA } & \multicolumn{2}{|c|}{ AAK } \\
\hline & & & & & & & & & & & & \\
\hline Coconut & 110 & 0.404 & 2 & 0.029 & 30 & 0.341 & 132 & 0.964 & 237 & 1.000 & 4 & 0.044 \\
\hline Forest & 140 & 0.515 & 61 & 0.897 & 12 & 0.136 & 5 & 0.036 & 0 & 0.000 & 72 & 0.791 \\
\hline Oil palm & 19 & 0.070 & 3 & 0.044 & 36 & 0.409 & 0 & 0.000 & 0 & 0.000 & 14 & 0.154 \\
\hline Other & 3 & 0.011 & 2 & 0.029 & 10 & 0.114 & 0 & 0.000 & 0 & 0.000 & 1 & 0.011 \\
\hline \multicolumn{13}{|l|}{ Maintenance } \\
\hline Absence & 29 & 0.107 & 6 & 0.088 & 20 & 0.227 & 2 & 0.015 & 20 & 0.085 & 23 & 0.250 \\
\hline Poor (bushy but accessible) & 100 & 0.368 & 23 & 0.338 & 36 & 0.409 & 63 & 0.460 & 166 & 0.703 & 49 & 0.533 \\
\hline Good (easily accessible) & 109 & 0.401 & 23 & 0.338 & 15 & 0.170 & 69 & 0.504 & 47 & 0.199 & 16 & 0.174 \\
\hline Very good (no weeds, no bush) & 34 & 0.125 & 16 & 0.235 & 17 & 0.193 & 3 & 0.022 & 3 & 0.013 & 4 & 0.043 \\
\hline \multicolumn{13}{|l|}{ Use of herbicide } \\
\hline No herbicide & 218 & 0.810 & 55 & 0.809 & 80 & 0.920 & 120 & 0.960 & 204 & 0.919 & 70 & 0.787 \\
\hline Herbicide & 51 & 0.190 & 13 & 0.191 & 7 & 0.080 & 5 & 0.040 & 18 & 0.081 & 19 & 0.213 \\
\hline \multicolumn{13}{|l|}{ Frequency of herbicide } \\
\hline Once & 34 & 0.667 & 6 & 0.462 & 5 & 0.714 & 5 & 1.000 & 12 & 0.667 & 6 & 0.316 \\
\hline Twice & 15 & 0.294 & 5 & 0.385 & 2 & 0.286 & 0 & 0.000 & 6 & 0.333 & 12 & 0.632 \\
\hline Thrice & 2 & 0.039 & 2 & 0.154 & 0 & 0.000 & 0 & 0.000 & 0 & 0.000 & 1 & 0.053 \\
\hline
\end{tabular}

In each district, left column refers to number of plots and right column to proportion of plots in the district. 
Table 6. Distribution of plots according to history after coconut planting and district.

\begin{tabular}{|c|c|c|c|c|c|c|c|c|c|c|c|c|}
\hline \multirow[b]{2}{*}{ Pueraria } & \multicolumn{2}{|c|}{ Nzema East } & \multicolumn{2}{|c|}{ Wassa West } & \multicolumn{2}{|c|}{ Ahanta West } & \multicolumn{2}{|c|}{ SAEMA } & \multicolumn{2}{|l|}{ KEEA } & \multicolumn{2}{|c|}{ AAK } \\
\hline & 76 & 0.278 & 29 & 0.426 & 31 & 0.352 & 3 & 0.022 & 12 & 0.051 & 0 & 0.000 \\
\hline Chromolaena & 125 & 0.458 & 32 & 0.471 & 61 & 0.693 & 67 & 0.489 & 213 & 0.899 & 22 & 0.239 \\
\hline Grasses & 54 & 0.198 & 1 & 0.015 & 22 & 0.250 & 50 & 0.365 & 224 & 0.945 & 78 & 0.848 \\
\hline Shrubs & 48 & 0.176 & 5 & 0.074 & 47 & 0.534 & 61 & 0.445 & 10 & 0.042 & 81 & 0.880 \\
\hline Cassava & 270 & 0.989 & 63 & 0.926 & 27 & 0.307 & 132 & 0.964 & 184 & 0.776 & 57 & 0.620 \\
\hline Plantain & 74 & 0.271 & 28 & 0.412 & 9 & 0.102 & 32 & 0.234 & 9 & 0.038 & 10 & 0.109 \\
\hline Pepper & 126 & 0.462 & 5 & 0.074 & 0 & 0.000 & 9 & 0.066 & 40 & 0.169 & 36 & 0.391 \\
\hline Tomato & 42 & 0.154 & 0 & 0.000 & 1 & 0.011 & 2 & 0.015 & 68 & 0.287 & 38 & 0.413 \\
\hline Eggplant & 14 & 0.051 & 1 & 0.015 & 1 & 0.011 & 7 & 0.051 & 78 & 0.329 & 16 & 0.174 \\
\hline Pineapple & 62 & 0.227 & 3 & 0.044 & 1 & 0.011 & 4 & 0.029 & 2 & 0.008 & 1 & 0.011 \\
\hline Maize & 201 & 0.736 & 54 & 0.794 & 15 & 0.170 & 114 & 0.832 & 208 & 0.878 & 90 & 0.978 \\
\hline Oil palm & 2 & 0.007 & 3 & 0.044 & 18 & 0.205 & 1 & 0.007 & 2 & 0.008 & 1 & 0.011 \\
\hline Sugarcane & 5 & 0.018 & 0 & 0.000 & 2 & 0.023 & 14 & 0.102 & 2 & 0.008 & 9 & 0.098 \\
\hline
\end{tabular}

In each district, left column refers to number of plots and right column to the ratio (number of plots)/(total number of plots in the district).

where it is good or very good in more than $50 \%$ of the plots.

The distribution of crops or weeds after coconut planting is presented in table 6. Some of these factors are highly discriminant for districts. As examples, the proportion of plots with Pueraria is greater than 0.27 in Nzema East, Wassa West and Ahanta West, whereas it is lower than 0.06 in SAEMA, KEEA and AAK. The proportion of plots with grasses is greater in KEEA (0.945) and AAK (0.848) than in the other districts. The proportion of plots with oil palm is greater in Ahanta West (0.205) than in the other districts (lower than 0.05).

\section{Incidence}

\section{Statistical distribution}

Tree incidence lay between 0 and 0.7 with only 36 values greater than 0 . This gives a very overdispersed distribution (figure 1), which has to be considered in the statistical analysis procedures.

\section{Geographical distribution}

The highest Tree and Plot incidences (figure 2 and table 7) occur in AAK and KEEA, whereas Wassa West, Ahanta West and SAEMA have relatively low incidences. Nzema East has an intermediate situation.

\section{Relation between incidence and outside variables}

Significant effects on Plot and/or Tree incidence were obtained for factors planting, district (table 7), slope, soil colour, soil texture, maintenance, Pueraria, Chromolaena, Cassava and tomato (table 8).

\section{Planting}

The highest Tree incidence occurred for planting year 2001. Plot incidence was higher for older plantations (planting years 1999, 2000 and 2001) than for younger plantations (planting years 2002, 2003 and 2004) (table 9).

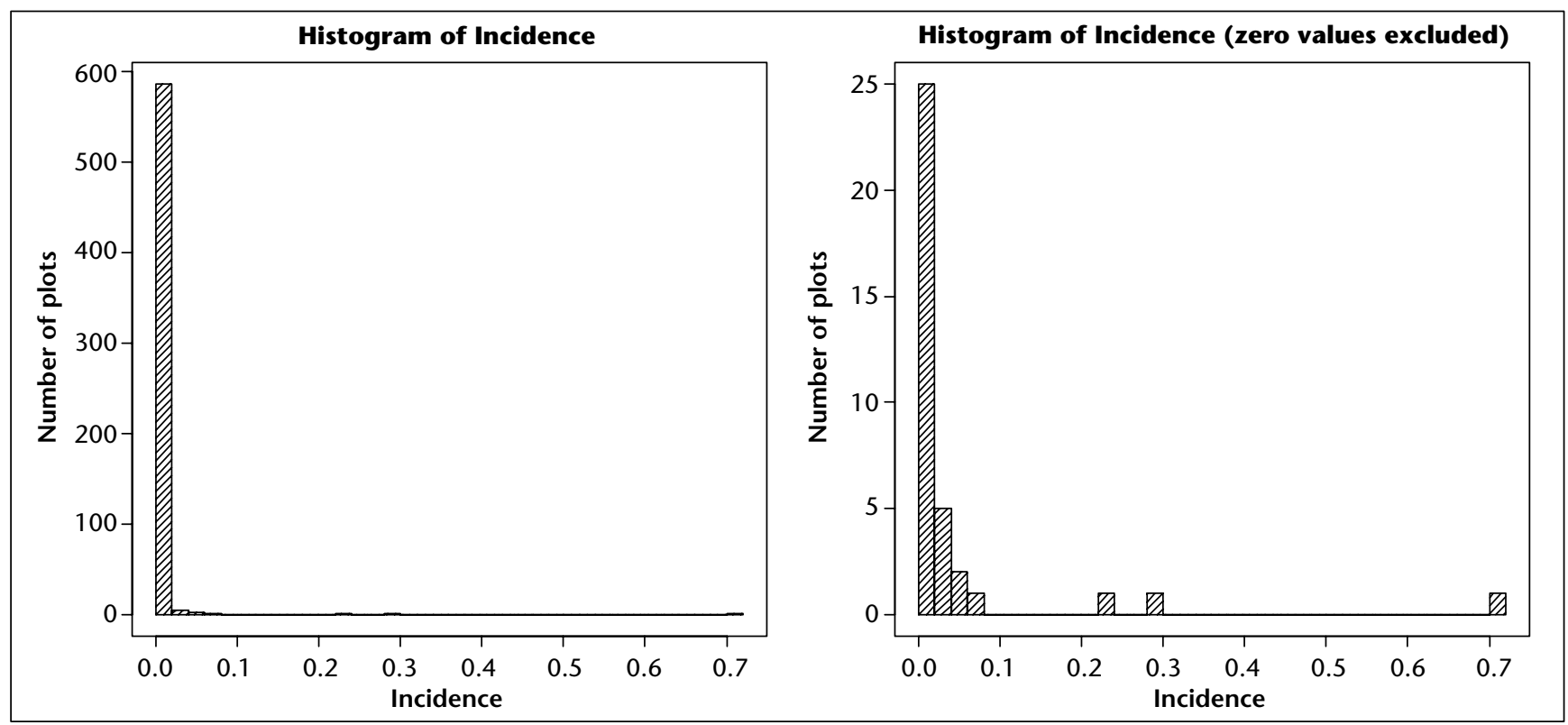

Figure 1. Distribution of Tree incidence of CSPWD. Left: all values included. Right: zero values excluded. 


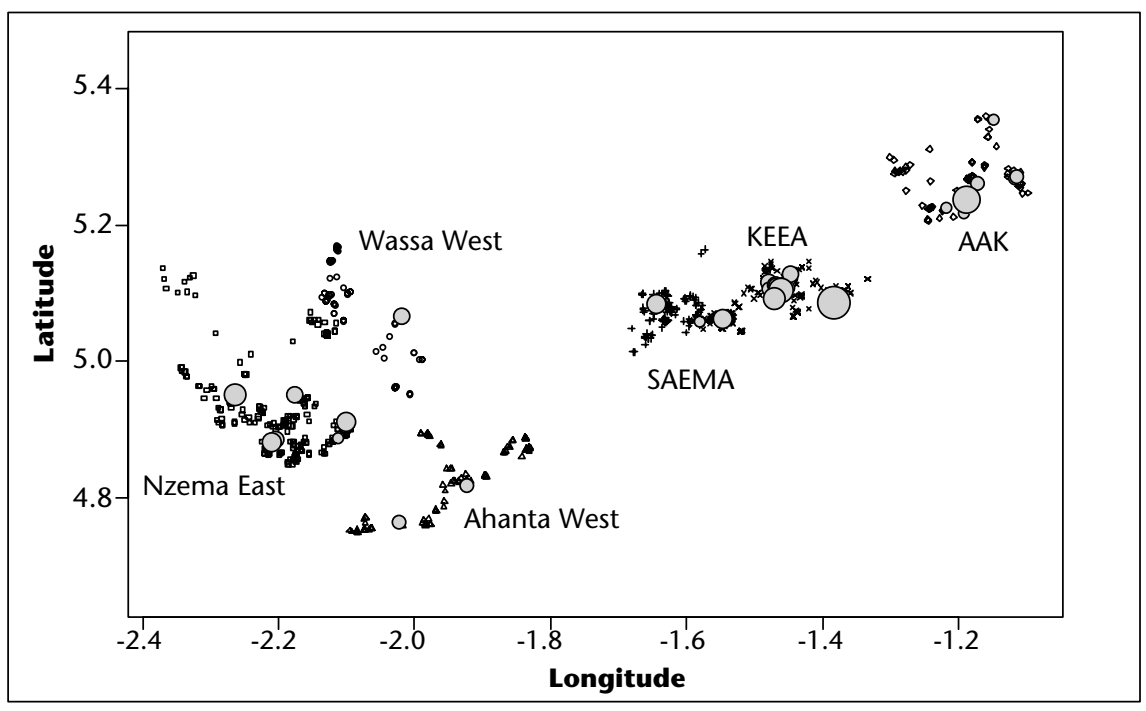

Figure 2. Geographical distribution of CSPWD in Western and Central regions in Chana. Black symbols: healthy plots. Grey circles: diseased plots. The larger the radius, the higher the incidence.

\section{Slope}

Plot and Tree incidence are higher on flat slopes and are decreasing when the slope becomes steeper (table 10).

\section{Soil colour}

Tree incidence is higher on dark-coloured soils (black, dark brown, dark grey) than on lightcoloured soils (table 11).

\section{Soil texture}

Tree and Plot incidence are higher on heavy soils than on light soils (table 12).

\section{Maintenance}

Tree incidence is increasing from absence of maintenance to good maintenance (table 13).

\section{Pueraria, Chromolaena, Cassava, Tomato}

There is a negative correlation between Tree or Plot incidence and presence of Pueraria, Chromolaena and Cassava. For Tomato, the correlation is slightly positive (table 14).

\section{Discussion}

This preliminary study made it possible to characterize the distribution of CSPWD incidence and the distribution of hydrography, topography, soil, agronomical and ecological data. Relations between incidence and outside variables were investigated. The values of the outside variables as well as incidence of CSPWD were found to differ strongly according to the district. The highest incidences of CSPWD were found in AAK and KEEA, and the lowest incidences in Wassa West, Ahanta West and SAEMA. A correlation was detected between Plot and/or Tree incidence and factors planting, district, slope, soil colour, soil texture, maintenance, Pueraria, Chromolaena, Cassava, tomato. However, these correlations are not easy to interpret. The correlation of incidence with planting date could merely reflect the natural increase of incidence with time. The correlation with topographic and soil variables could be only a consequence of very different situations in different districts, without any direct causal relation. Indeed, it can be verified that outside variables are very correlated, so that it is difficult to separate their effects. This could be done by introducing together many factors into the model. This has been tried, but several difficulties then arise because of no convergence of al-
Table 8. $P$ values of Fisher's exact test (Plot incidence) and logistic regression (Tree incidence).

\begin{tabular}{|lll|}
\hline & $\begin{array}{l}\text { Plot } \\
\text { incidence }\end{array}$ & $\begin{array}{l}\text { Tree } \\
\text { incidence }\end{array}$ \\
\hline Planting year & $0.0283^{*}$ & $0.0175^{*}$ \\
District & $0.0002^{* *}$ & 0.0795 \\
Presence of water & 0.1718 & 0.8884 \\
Distance of water & 0.0979 & 0.0782 \\
Is the plot floodable? & 0.1379 & 0.8723 \\
Location of the plot & 0.3514 & 0.8328 \\
(topography) & & \\
Slope & 0.3457 & $0.0239^{*}$ \\
Soil colour & $0.0125^{*}$ & $0.0014^{* *}$ \\
Soil texture & 0.0780 & $0.0179^{*}$ \\
Presence of coarse & 0.2906 & 0.7223 \\
elements & & \\
Previous land & 0.3179 & 0.8170 \\
occupation & & \\
Year when LY killed & 0.9270 & 0.5821 \\
the first coconut & & \\
Maintenance & 0.2854 & $0.0149^{*}$ \\
Use of herbicide & 0.1697 & 0.4615 \\
Frequency of & 0.5676 & 0.5462 \\
herbicide & & \\
Use of fertilizer & 1.0000 & 0.7636 \\
Is there LY around? & 0.0549 & 0.5776 \\
Pueraria & $0.0298^{*}$ & 0.2122 \\
Chromolaena & $0.0085^{* *}$ & $0.0060^{* *}$ \\
Grasses & 0.0862 & 0.8854 \\
Shrubs & 0.1293 & 0.7475 \\
Cassava & $0.0077^{* *}$ & $0.0014^{* *}$ \\
Plantain & 0.5167 & 0.4624 \\
Pepper & 0.0588 & 0.4990 \\
Tomato & $0.0389^{*}$ & 0.6624 \\
Eggplant & 0.4426 & 0.6380 \\
Pineapple & 0.7563 & 0.5834 \\
Maize & 0.6867 & 0.1777 \\
Ooil palm & 0.6196 & 0.5861 \\
Sugarcane & 0.1206 & 0.7671 \\
\hline
\end{tabular}

*Significant at level 0.05 ; **significant at level 0.01 .

gorithms or high dependence of order of introduction of the factors on the results. The negative correlation of incidence with Chromolaena and with Pueraria (although lower in the latter case) could be due to a

Table 7. Plot and Tree incidence according to district.

\begin{tabular}{|lclllcl|}
\hline District & Healthy plots & Diseased plots & Plot incidence & Healthy trees & Diseased trees & Tree incidence \\
\hline Nzema East & 161 & 6 & 0.036 & 39,710 & 34 & 0.00086 \\
Wassa West & 52 & 1 & 0.019 & 13,271 & 2 & 0.00015 \\
Ahanta West & 60 & 2 & 0.032 & 14,717 & 3 & 0.00020 \\
SAEMA & 78 & 2 & 0.025 & 19,493 & 11 & 0.00056 \\
KEEA & 165 & 11 & 0.062 & 36,080 & 168 & 0.00463 \\
AAK & 58 & 14 & 0.194 & 16,432 & 128 & 0.00773 \\
\hline
\end{tabular}


Table 9. Plot and tree incidence according to planting year.

\begin{tabular}{|lcclcrc|}
\hline Planting year & Healthy plots & Diseased plots & Plot incidence & Healthy trees & Diseased trees & Tree incidence \\
\hline 1999 & 17 & 2 & 0.105 & 4,956 & 12 & 0.00242 \\
2000 & 149 & 12 & 0.075 & 42,047 & 49 & 0.00116 \\
2001 & 74 & 10 & 0.119 & 22,125 & 201 & 0.00900 \\
2002 & 128 & 7 & 0.052 & 29,194 & 24 & 0.00082 \\
2003 & 141 & 3 & 0.021 & 26,991 & 57 & 0.00211 \\
2004 & 65 & 2 & 0.030 & 14,390 & 3 & 0.00021 \\
\hline
\end{tabular}

Table 10. Plot and Tree incidence according to slope.

\begin{tabular}{|lllllcc|}
\hline Slope & Healthy plots & Diseased plots & Plot incidence & Healthy trees & Diseased trees & Tree incidence \\
\hline Flat & 293 & 23 & 0.073 & 71,079 & 295 & 0.00413 \\
Low & 117 & 5 & 0.041 & 30,093 & 23 & 0.00076 \\
Medium & 108 & 4 & 0.036 & 24,016 & 7 & 0.00029 \\
Steep & 21 & 0 & 0.000 & 4,968 & 0 & 0.00000 \\
\hline
\end{tabular}

Table 11. Plot and Tree incidence according to soil colour.

\begin{tabular}{|lcclcrc|}
\hline Soil colour & Healthy plots & Diseased plots & Plot incidence & Healthy trees & Diseased trees & Tree incidence \\
\hline Black & 30 & 6 & 0.167 & 8,629 & 101 & 0.01157 \\
Dark brown & 88 & 8 & 0.083 & 19,905 & 151 & 0.00753 \\
Dark grey & 35 & 2 & 0.054 & 7,713 & 15 & 0.00194 \\
Dark red & 21 & 1 & 0.045 & 4,783 & 1 & 0.00021 \\
Light brown & 129 & 11 & 0.079 & 32,035 & 23 & 0.00072 \\
Light grey & 208 & 8 & 0.037 & 53,860 & 55 & 0.00102 \\
Light red & 63 & 0 & 0.000 & 12,778 & 0 & 0.00000 \\
\hline
\end{tabular}

Table 12. Plot and Tree incidence according to soil texture.

\begin{tabular}{|llllrlc|}
\hline Soil texture & Healthy plots & Diseased plots & Plot incidence & Healthy trees & Diseased trees & Tree incidence \\
\hline Heavy & 144 & 14 & 0.089 & 33,889 & 213 & 0.00625 \\
Light & 429 & 22 & 0.049 & 105,446 & 133 & 0.00126 \\
\hline
\end{tabular}

Table 13. Plot and Tree incidence according to maintenance.

\begin{tabular}{|lccllrr|}
\hline Maintenance & Healthy plots & Diseased plots & Plot incidence & Healthy trees & Diseased trees & Tree incidence \\
\hline Absence & 76 & 1 & 0.013 & 14,800 & 2 & 0.00014 \\
Poor (bushy but accessible) & 281 & 21 & 0.070 & 69,726 & 53 & 0.00076 \\
Good (easily accessible) & 166 & 11 & 0.062 & 41,754 & 240 & 0.00572 \\
Very good (no weeds, no bush) & 50 & 3 & 0.057 & 13,055 & 51 & 0.00389 \\
\hline
\end{tabular}

Table 14. Plot and Tree incidence according to presence of Pueraria, Chromolaena, Cassava and tomato.

\begin{tabular}{|c|c|c|c|c|c|c|}
\hline & Healthy plots & Diseased plots & Plot incidence & Healthy trees & Diseased trees & Tree incidence \\
\hline \multicolumn{7}{|l|}{ Pueraria } \\
\hline Absence & 481 & 35 & 0.068 & 11,7193 & 344 & 0.00293 \\
\hline Presence & 93 & 1 & 0.011 & 22,510 & 2 & 0.00009 \\
\hline \multicolumn{7}{|c|}{ Chromolaena } \\
\hline Absence & 221 & 22 & 0.091 & 59,099 & 294 & 0.00495 \\
\hline Presence & 353 & 14 & 0.038 & 80,604 & 52 & 0.00064 \\
\hline \multicolumn{7}{|l|}{ Cassava } \\
\hline Absence & 106 & 14 & 0.117 & 29,232 & 229 & 0.00777 \\
\hline Presence & 468 & 22 & 0.045 & 110,471 & 117 & 0.00106 \\
\hline \multicolumn{7}{|l|}{ Tomato } \\
\hline Absence & 480 & 25 & 0.050 & 115,692 & 253 & 0.00218 \\
\hline Presence & 94 & 11 & 0.105 & 24,011 & 93 & 0.00386 \\
\hline
\end{tabular}


competition between these species and weeds, potentially, the hosts of the vector. However the main issues remain the reliability of data and the relatively low number of CSPWD cases observed, which cannot lead to strongly significant results. More sophisticated statistical procedures need to be investigated in order to take into account the overdispersion and the possible spatial autocorrelation of the incidence of the disease.

\section{REFERENCES}

1. Agresti A. Categorical Data Analysis. New York: John Wiley \& Sons, 1990.

2. Bonnot F. Epidemiology of Coconut Lethal Yellowing in Ghana. Report on the mission from 20 February to 2 March 2007. CIRADBIOS. Rapport n³2, 2007.
3. Madden LV, Hughes G, Van Den Bosch F. The study of plant disease epidemics. APS Press, Saint Paul, 2007.

4. McCullagh P, Nelder JA. Generalized linear Models. London: Chapman \& Hall, 1989.

5. Philippe R. Report on the mission to Ghana from $19 / 11$ to $2 / 121994$. Studies on insect vectors of the coconut mycoplasma disease in Ghana. Doc CP No. 350, 1995. 